\title{
The distribution-free newsboy problem with resalable returns
}

\author{
Julien Mostard, Rene de Koster and Ruud Teunter
}

\begin{tabular}{|l|l|}
\hline \multicolumn{2}{|l|}{ ERIM REPORT SERIES RESEARCH IN MANAGEMENT } \\
\hline ERIM Report Series reference number & ERS-2003-068-LIS \\
\hline Publication & 2003 \\
\hline Number of pages & 23 \\
\hline Email address corresponding author & jmostard@fbk.eur.nl \\
\hline Address & Erasmus Research Institute of Management (ERIM) \\
& Rotterdam School of Management / Faculteit Bedrijskunde \\
& Rotterdam School of Economics / Faculteit \\
& Economische Wetenschappen \\
& Erasmus Universiteit Rotterdam \\
& P.O. Box 1738 \\
& 3000 DR Rotterdam, The Netherlands \\
& Phone: +31 10 408 1182 \\
& Fax: $\quad+31$ 10 408 9640 \\
& Email: info@erim.eur.nl \\
& Internet: $\quad$ www.erim.eur.nl \\
\hline
\end{tabular}

Bibliographic data and classifications of all the ERIM reports are also available on the ERIM website: www.erim.eur.nl 


\title{
ERASMUS RESEARCH INSTITUTE OF MANAGEMENT
}

\author{
REPORT SERIES \\ RESEARCH IN MANAGEMENT
}

\begin{tabular}{|c|c|c|}
\hline \multicolumn{3}{|c|}{ BIBLIOGRAPHIC DATA AND CLASSIFICATIONS } \\
\hline Abstract & \multicolumn{2}{|c|}{$\begin{array}{l}\text { We study the case of a catalogue/internet mail order retailer selling seasonal products } \\
\text { and receiving large numbers of commercial returns. Returned products arriving before } \\
\text { the end of the selling season can be resold if there is sufficient demand. A single order } \\
\text { is placed before the season starts. Excess inventory at the end of the season is salvaged } \\
\text { and all demands not met directly are lost. Since little historical information is available, } \\
\text { it is impossible to determine the shape of the distribution of demand. Therefore, we } \\
\text { analyze the distribution-free newsboy problem with returns, in which only the mean and } \\
\text { variance of demand are assumed to be known. We derive a simple closed-form expression } \\
\text { for the distribution-free order quantity, which we compare to the optimal order quantities when } \\
\text { gross demand is assumed to be normal, lognormal or uniform. We find that the distribution-free } \\
\text { order rule performs well in most realistic cases. }\end{array}$} \\
\hline \multirow{3}{*}{$\begin{array}{l}\text { Library of Congress } \\
\text { Classification } \\
\text { (LCC) }\end{array}$} & $5001-6182$ & Business \\
\hline & $5201-5982$ & Business Science \\
\hline & HD 30.27 & Forecasting \\
\hline \multirow{3}{*}{$\begin{array}{l}\text { Journal of Economic } \\
\text { Literature } \\
(\mathrm{JEL})\end{array}$} & M & Business Administration and Business Economics \\
\hline & $\begin{array}{l}\text { M } 11 \\
\text { R } 4\end{array}$ & $\begin{array}{l}\text { Production Management } \\
\text { Transportation Systems }\end{array}$ \\
\hline & C 61 & Optimization Techniques, Programming models, Dynamic Analysis \\
\hline \multirow{4}{*}{$\begin{array}{l}\text { European Business Schools } \\
\text { Library Group } \\
\text { (EBSLG) }\end{array}$} & $85 \mathrm{~A}$ & Business General \\
\hline & $260 \mathrm{~K}$ & Logistics \\
\hline & $240 \mathrm{~B}$ & Information Systems Management \\
\hline & $250 \mathrm{E}$ & Forecasting \\
\hline \multicolumn{3}{|c|}{ Gemeenschappelijke Onderwerpsontsluiting (GOO) } \\
\hline \multirow[t]{4}{*}{ Classification GOO } & 85.00 & Bedrijfskunde, Organisatiekunde: algemeen \\
\hline & 85.34 & Logistiek management \\
\hline & 85.20 & Bestuurlijke informatie, informatieverzorging \\
\hline & 85.03 & Methoden en technieken, Operations research \\
\hline \multirow[t]{3}{*}{ Keywords GOO } & \multicolumn{2}{|c|}{ Bedrijfskunde / Bedrijfseconomie } \\
\hline & \multicolumn{2}{|c|}{ Bedrijfsprocessen, logistiek, management informatiesystemen } \\
\hline & \multicolumn{2}{|c|}{ Voorraden, vraag en aanbod, producten, teruggave, wiskundige modellen } \\
\hline Free keywords & \multicolumn{2}{|c|}{ Inventory, distribution-free newsboy problem, product returns } \\
\hline
\end{tabular}




\title{
The distribution-free newsboy problem with resalable returns
}

\author{
Julien Mostard* René de Koster \\ Rotterdam School of Management, Erasmus University Rotterdam, The Netherlands \\ Ruud Teunter \\ Faculty of Economics, Erasmus University Rotterdam, The Netherlands
}

September 5, 2003

\begin{abstract}
We study the case of a catalogue/internet mail order retailer selling seasonal products and receiving large numbers of commercial returns. Returned products arriving before the end of the selling season can be resold if there is sufficient demand. A single order is placed before the season starts. Excess inventory at the end of the season is salvaged and all demands not met directly are lost. Since little historical information is available, it is impossible to determine the shape of the distribution of demand. Therefore, we analyze the distribution-free newsboy problem with returns, in which only the mean and variance of demand are assumed to be known. We derive a simple closed-form expression for the distribution-free order quantity, which we compare to the optimal order quantities when gross demand is assumed to be normal, lognormal or uniform. We find that the distribution-free order rule performs well in most realistic cases.
\end{abstract}

Keywords: inventory, distribution-free newsboy problem, product returns

${ }^{*}$ Corresponding author. Address: P.O.Box 1738, 3000 DR Rotterdam, The Netherlands. Tel.: +31-(0)104082007. Fax: +31-(0)10-4089014. E-mail: jmostard@fbk.eur.nl. 


\section{Introduction}

In many countries, customers have the legal right to return unused purchases within a specified number of days after purchase, especially in the case of distant selling. The original purchase cost is then partially or fully reimbursed. As a result of this right, retailers selling products via mail order or over the internet generally have to deal with large volumes of returns. Because the sales process is remote, customers cannot see, feel and try the actual product, which often leads to a wrong decision. Common reasons for returning are a wrong size, a change of mind (remorse) or the fact that the actual color differs slightly from the displayed one.

The presence of return flows changes inventory control significantly (Fleischmann et al., 1997). First, the retailer has little control over the return flow in terms of quantity, quality and timing. Second, ordering decisions and processing of returned products have to be coordinated, since returned products can be resold in most cases. The higher the return rates, the more important these factors become. In the case of a mail order/internet retailer that we consider, return rates are usually larger than $18 \%$ and can be as high as $74 \%$ for specific products (Mostard and Teunter, 2002).

The management of return flows has received growing attention in the past decade. The whole of logistic activities to collect, disassemble and recover (parts of) used products or materials for the purpose of recapturing value or proper disposal is known as reverse logistics (Revlog website, 1999 and Rogers and Tibben-Lembke, 1999).

Much research in this field has been dedicated to the implications of return flows for the areas of distribution planning, inventory control and production planning. Fleischmann et al. (1997) have performed a review of the mathematical models that have been proposed in this context. However, the vast majority of the proposed inventory control models for reverse logistics concentrate either at returns that need extensive recovery (e.g. repair or remanufacturing) or at end-of-life products destined for recycling. In our case, the returned products are generally in an as-good-as-new condition and can be resold directly after testing and possibly repackaging provided there is enough demand and they are returned before the end of the selling season (in the case of seasonal products).

We consider the inventory control problem for the case of a mail order/internet retailer selling fashion products. Besides the high return rates, seasonality, large supply lead times and lack of data are three important factors in this case that complicate inventory control. These are all related to the type of product, fashion clothing. We will next discuss each factor separately.

Fashion products are seasonal. Fisher and Raman (1996) note that most fashion apparel 
companies introduce a completely new product line every season which must be designed and produced in time to be sold during a concentrated retail selling season. They also point out that the costs of excess inventory that must be sold below purchase cost at the end of the season and of lost sales due to stockouts are high in the apparel industry because of unpredictable demand and a complex supply chain.

The supply lead times of fashion products are usually long. Therefore, retailers have to settle their entire season's order quantities well before they have an opportunity to observe actual sales performances (Mantrala and Raman, 1999). Because of this single order opportunity, it is natural to use a newsboy type model for analyzing our problem. However, the standard newsboy model (see Silver et al., 1998 and Khouja, 1999 for literature reviews) does not allow for returns.

Only recently, Vlachos and Dekker (2003) first studied ordering policies for single-period products with returns. They extend the newsboy problem while making two simplifying assumptions. First, they assume that products can be resold only once. Second, they assume that a fixed percentage of sold products is returned and resalable. Considering several different return options, based on different handling of the returned products, they derive optimal order quantities for the various models resulting from these options. By numerical experiments, they show that the optimal classical newsboy quantity is far from optimal when return rates are high.

In a following study, Mostard and Teunter (2002) argue that the two assumptions underlying the model of Vlachos and Dekker lead to a suboptimal order quantity. In practice products can be returned and resold several times during a season, which contradicts the first assumption. Moreover, due to the second assumption, part of the variability in the number of (resalable) returns, given gross demand, is ignored. Mostard and Teunter drop these assumptions. Taking a net demand approach, they derive a simple closed-form equation that determines the optimal order quantity given the gross demand distribution, the probability that a sold product is returned, and all relevant revenues and costs. Using real data, they compare this optimal order quantity to both the order quantity proposed by Vlachos and Dekker and to the company's order quantity. The former generally differs more than $10 \%$ from the optimal order quantity, while the associated reduction in profit is generally small but can be large is specific cases. The latter turns out to be far from optimal.

There is a lack of historical data of fashion products. In order to determine the order quantity of a certain product, retailers need reasonable estimates of the return rate and the distribution of demand. But for obtaining reliable estimates one needs historical data. Due to 
seasonality, only limited historical data of similar products are available. These are often at most sufficient for estimating the return rate and the first two moments of demand. But since the fashion goods market is characterized by high demand variability and highly unpredictable consumer preferences (Jain and Paul, 2001), they are usually insufficient for determining the shape of the demand distribution. This certainly holds for the specific case study that motivates this research. We therefore explore the distribution-free newsboy model in this paper. Distribution-free means that only the first two moments of demand are assumed to be known. Gallego and Moon (1993) first studied the distribution-free newsboy problem. They prove the optimality of Scarf's ordering rule for this problem. This rule finds the order quantity that maximizes expected profit against the worst possible demand distribution with a certain mean and variance (Scarf, 1958). The maximum amount that can be gained by knowing the complete demand distribution is shown to be negligible for most practical problems. This is shown for a variety of cases: the recourse case, the fixed ordering cost case, the random yield case and the multi-product case.

Since the paper of Gallego and Moon, the distribution-free approach has been adopted in several other studies (see, e.g., Moon and Choi, 1995, 1998 and Silver and Moon, 2001). Numerical examples in these papers all show that Scarf's ordering rule is near optimal in a distribution-free setting and that it is robust. Furthermore, it is computationally simple and easy to understand, which makes it valuable in practice.

In this article, we apply the distribution-free approach to the single-period problem with returns. We compare the resulting order quantity and corresponding expected profit to the optimal order quantity and expected profit (in the case that the complete demand distribution is known). In this way, we determine the value of additional demand information, i.e. the extra profit that can be gained by knowing the complete distribution of demand instead of its first two moments. We will do this for a wide range of parameter values and under the assumption that gross demand is either normal, lognormal or uniform.

The remainder of this paper is organized as follows. In section 2, we introduce the notation and the assumptions underlying underlying our distribution-free newsboy model. The distribution-free order quantity is derived in section 2.1. In section 4, we compare the distributionfree order quantity and expected profit to the optimal order quantity and expected profit for a wide range of parameters. But in order to compute the optimal order quantity and associated expected profit we need to know the distribution of net demand. Therefore, in section 3, we will first examine the shape of the net demand distribution under the assumption that gross demand is normal, lognormal or uniform, to see whether net demand follows the same type of 
distribution. Finally, we present our main findings and conclusions in section 5.

\section{Model and assumptions}

There is a single order opportunity. The order of size $Q$ arrives before the start of the season. The retailer pays a cost $c$ per ordered product and receives a sales price $p$ for every sold product. A product that has been delivered to a customer has a probability $r$ of being returned. The retailer incurs a collection cost $d$ for every returned product. There is no return fee for the customer.

An returned product is resalable if it is undamaged and if there is still enough demand to resell it (so it has to be back before the end of the selling season). We thereby assume priority of resales over first sales. Note that this assumption is only necessary for defining the notion of a resalable return, since returned products are of the same quality and sold against the same price as first sales.

We assume that every return is resalable with probability $k$ and that this probability is fixed and known. This probability can be estimated well in practice (De Koster and Zuidema, 2002).

Over the whole season, the total number of gross demanded products is $G$, with mean $\mu_{G}$ and standard deviation $\sigma_{G}$. In case of a stockout, every demand that cannot be met results in a shortage cost $g$. Every unsold product at the end of the season is sold in a secondary market, yielding a salvage value $v$.

The objective is to determine the order quantity $Q$ that maximizes expected profit.

The optimal order decision has to account for returns, so we should consider net demand rather than gross demand. Therefore, as in Mostard and Teunter (2002), we will base our analysis on net demand rather than gross demand. We need some additional notation for this.

Every gross demanded product results in a net demand if it is either not returned or returned but not resalable, assuming that there is sufficient stock to meet gross demand. Thus, net demand $N$ follows from the number of gross demands by subtracting the number of times that a product is both returned and resalable during the season. Note that returned products which are damaged or which arrive after the end of the season are also included in the net demand. This is to ascertain that, with a reasonable probability, there is enough stock to meet all gross demands. Net demand has mean $\mu_{N}$ and standard deviation $\sigma_{N}$, which can be computed from the expectation and standard deviation of gross demand as follows (see, e.g., Kelle and Silver, 
1989 or Mostard and Teunter, 2002).

$$
\mu_{N}=(1-r k) \mu_{G} \quad \text { and } \quad\left(\sigma_{N}\right)^{2}=(1-r k)^{2}\left(\sigma_{G}\right)^{2}+r k(1-r k) \mu_{G}
$$

The unit expected revenue of satisfying a gross demand equals $p_{G}=(1-r) p-r d+r(1-k) v$. This can be seen as follows. The retailer incurs the sales price $p$ for every product which is not returned, resulting in a per unit expected revenue of $(1-r) p$. For every product that is returned by a customer, the retailer pays collection cost $d$, resulting in a per unit expected cost of $r d$. There is a probability $r(1-k)$ that a returned product is not resalable, in which case it yields salvage value $v$. Thus, the per unit expected revenue in this case is $r(1-k) v$.

If a product is sold repeatedly until it is either not returned or not resalable, then the unit expected revenue of satisfying this net demand is $p_{N}=p_{G}\left[1+r k+(r k)^{2}+\ldots\right]=p_{G} /(1-r k)$. Similarly, the expected shortage cost of not satisfying a net demand is $g_{N}=g /(1-r k)$. Note that the number of times that a single product can be returned and resold is only restricted by the length of the season.

All notations that have been introduced above and some additional notations that will be used in the remainder are summarized in Table 1.

\section{INSERT TABLE 1 ABOUT HERE}

\subsection{The distribution-free order quantity}

Every net demand that can be met from the stock of $Q$ purchased products yields expected revenue $p_{N}$. Recall that this includes the salvage value if a product is returned but not resalable. Every unit in stock that is never delivered to a customer (i.e. for which there is no gross demand) also yields salvage value $v$. In case total net demand is larger than the initial stock $Q$, the shortage of stock costs $g_{N}$ per unit. Hence, the total expected net profit is

$$
\begin{aligned}
E P(Q) & =p_{N}\left(\mu_{N}-E S_{N}(Q)\right)-c Q-g_{N} E S_{N}(Q)+v\left(Q-\left(\mu_{N}-E S_{N}(Q)\right)\right) \\
& =\left(p_{N}-v\right) \mu_{N}-(c-v) Q-\left(p_{N}-v+g_{N}\right) E S_{N}(Q)
\end{aligned}
$$

Here, $E S_{N}$ denotes the expected net shortage, i.e., the expected number of net demands not met.

The expected profit function in (1) is the same as the classical newsboy expected profit function, but the parameters have been rewritten to represent the net demand case. A difference is that the profit function in the classical newsboy problem is based on gross demand, while we use a net demand approach. 
As is shown in Mostard and Teunter (2002), the optimal order quantity $Q^{\star}$ for this problem that maximizes the expected profit in (1) is

$$
Q^{\star}=F_{N}^{-1}\left(\frac{\left(p_{N}-s+g_{N}\right)-(c-s)}{\left(p_{N}-s+g_{N}\right)}\right)
$$

where $F_{N}(\cdot)$ denotes the cumulative distribution function (cdf) of net demand.

Since no more than $Q$ net demands can be satisfied, the expected net shortage is

$$
E S_{N}(Q)=E[N-Q]^{+}
$$

Clearly, maximizing $E P(Q)$ is equivalent to minimizing

$$
(c-v) Q+\left(p_{N}-v+g_{N}\right) E[N-Q]^{+} .
$$

Similar to the analysis in Gallego (1992) it can be shown that

$$
E[N-Q)]^{+} \leq \frac{\sqrt{\sigma_{N}^{2}+\left(Q-\mu_{N}\right)^{2}}-\left(Q-\mu_{N}\right)}{2}
$$

and that, for every $Q$, there exists a unique distribution in $\mathcal{G}$ for which this upper bound is tight.

The distribution-free approach is based on this 'worst case' distribution and thus minimizes

$$
(c-v) Q+\left(p_{N}-v+g_{N}\right) \frac{\sqrt{\sigma_{N}^{2}+\left(Q-\mu_{N}\right)^{2}}-\left(Q-\mu_{N}\right)}{2} .
$$

The optimal order quantity of the distribution-free approach follows by setting the derivative of (3) to zero and solving for $Q$, yielding (see appendix A for the derivation)

$$
\widetilde{Q}=\mu_{N}+\frac{\sigma_{N}}{2} \frac{1-2 x}{\sqrt{x(1-x)}},
$$

where $x=(c-v) /\left(p_{N}-v+g_{N}\right)$. The distribution-free order quantity, $\widetilde{Q}$, is equivalent to Scarf's order quantity (Scarf, 1958), adjusted for the case with returns and a penalty cost for lost sales. We remark that when $k=0$ or $r=0$, (4) reduces to the order quantity for the distribution-free case derived by Gallego and Moon (1993).

Let $e=Q-\mu_{N}$ and $f=p_{N}-v+g_{N}$. The second derivative of (3) equals (see the Appendix for the derivation)

$$
\frac{f \sigma_{N}^{2}}{2\left(\sigma_{N}^{2}+e^{2}\right) \sqrt{\sigma_{N}^{2}+e^{2}}} .
$$

The sign of this expression clearly depends on $f$. We may assume that $p_{N} \geq c$, since otherwise it would be impossible to make a positive profit and the order quantity would be zero. Since $c>v$, we get $p_{N}>v$ and thus $f>0$. Hence, the expression in (5) is strictly positive. Therefore, (3) is strictly convex in $Q$ and the optimal order quantity given by (4) is unique. 


\section{Comparing the shapes of gross and net demand}

In section 4 , we will compare the distribution-free order quantity $\widetilde{Q}$ to the optimal order quantity $Q^{\star}$, assuming that gross demand is either normal, lognormal, or uniform. As (2) shows, the cdf of net demand is needed to determine $Q^{\star}$. But an exact expression for this function is not available and cannot (easily) be derived from the cdf of gross demand. However, it seems reasonable to assume that net demand follows the same type of distribution as gross demand, i.e., net demand is assumed to be normal if gross demand is normal. In this section, we show that this is indeed a reasonable assumption.

For a large number of examples with normal, lognormal or uniform demand, we approximate the cdf of net demand using simulation and compare it to the normal, lognormal and uniform cdf with the same mean and variance. It will turn out that the two functions are nearly identical in almost all realistic cases.

We compare the approximate cdf of net demand to the cdf of gross demand for different combinations of the mean of gross demand, $\mu_{G}$, the coefficient of variation $(\mathrm{CV})$ of gross demand, $\sigma_{G} / \mu_{G}$, and the return percentage, $r$. These parameters influence the shape of the net demand distribution and can cause it to differ from that of the gross demand distribution. The parameter values that we use are shown in the first three rows of Table 2. All possible combinations of these parameters are explored.

\section{INSERT TABLE 2 ABOUT HERE}

The procedure for constructing the distribution of net demand is as follows. We take 5000 random drawings, $g_{i}, i=1,2, \ldots, 5000$, from the gross demand distribution. For each $g_{i}>1$, the corresponding number of resalable returns $r_{i}$ is drawn (once) from a binomial distribution with $g_{i}$ (rounded to the nearest integer) repetitions and probability of success $k r$. Computing $n_{i}=g_{i}-r_{i}$ then gives 5000 random values of net demand per product (parameter setting). The net demand distribution is obtained by assigning probability $1 / 5000$ to each of these.

Before the drawings from the uniform and lognormal distributions of gross demand can be taken, the parameters of these distributions have to be computed. They follow from the mean and standard deviation of gross demand as follows (see appendix B for the derivations).

The parameters $a$ and $b$ of the uniform distribution can be computed as

$$
a=\mu_{G}-\sqrt{3} \sigma_{G} \quad \text { and } \quad b=\mu_{G}+\sqrt{3} \sigma_{G} .
$$

The parameters $m$ and $s$ of the lognormal distribution follow from

$$
m=\ln \mu_{G}-0.5 \ln \left(1+\left(\sigma_{G} / \mu_{G}\right)^{2}\right) \quad \text { and } \quad s=\sqrt{\ln \left(1+\left(\sigma_{G} / \mu_{G}\right)^{2}\right)} .
$$


The cumulative distribution function (cdf) of net demand resulting from the above procedure is then plotted against the cdf of the normal, uniform or lognormal distribution with mean $\mu_{N}$ and standard deviation $\sigma_{N}$ to see whether they coincide.

We remark that for the normal and uniform distributions, a coefficient of variation greater than 0.5 , especially in combination with a high return rate, allows for negative drawings. Therefore, we only use $\mathrm{CV} \leq 0.5$ with these distributions.

The experiments show that the cdf of net demand almost coincides with that of the normal, lognormal or uniform distribution with mean $\mu_{N}$ and standard deviation $\sigma_{N}$ for most realistic parameter settings. Figures $1(\mathrm{a})$ through $1(\mathrm{k})$ depict a number of examples showing this.

For all return rates up to 0.75 (and thus all realistic parameter values), the two curves coincide nearly perfectly for both the lognormal and normal distributions. Figures 1(a) and 1(b) show two examples of this. Only in the case of a return percentage larger than $80 \%$ there can be a gap between the curves, which is only considerable when $r \geq 0.95$ and $\mathrm{CV}=0.1$, as is shown by Figures 1(c) through 1(f). These figures also show that the gap decreases when either $\mu_{G}$ or the coefficient of variation increases. Figures $1(\mathrm{~g})$ and $1(\mathrm{~h})$ show that the same holds for the normal distribution.

For the uniform distribution, Figures 1(i) through 1(k) show a slightly different situation. Figure 1(i) shows that already when $r=0.5$, the net demand curve clearly deviates from the uniform cdf with mean $\mu_{N}$ and standard deviation $\sigma_{N}$. When $r=0.95$, the gap between the two curves is rather large. As can be seen, net demand is not uniformly distributed in these cases. In fact, additionally plotting the normal cdf in Figures 1(i) and 1(j) showed that the net demand curve exactly coincides with the $N\left(\mu_{N}, \sigma_{N}\right)$-distributed cdf.

Thus, when gross demand is normal or lognormal, we can safely assume net demand to follow the same type of distribution with mean $\mu_{N}$ and standard deviation $\sigma_{N}$ in all realistic cases. When gross demand is uniform, the same holds for most realistic cases.

\section{Performance of the distribution-free order quantity}

Several studies (e.g., Gallego and Moon, 1993, Moon and Choi, 1995, 1998 and Silver and Moon, 2001) have shown that the distribution-free order rule is a good alternative to the classical newsboy rule when the exact form of the distribution function is unknown. For several types of demand distributions (normal, uniform, $\mathrm{t}$ and triangle), these studies have shown for a number of randomly generated parameter ranges that the expected value of additional information (the largest amount that one would be willing to pay for complete knowledge of 
the demand distribution) is very small.

In section 2.1, we have rewritten the classical newsboy expected profit function to represent the net demand case with product returns, yielding the profit function in (1). This function has the same form as the classical newsboy expected profit function that has been used in previous studies on the distribution-free order rule, the only difference being that it uses the distribution of net demand rather than gross demand. Based on the explorations of demand shapes in the previous section, we assume that net demand follows the same type of distribution as gross demand. Therefore, we expect the same sort of result as in the previous studies.

In this section, we will perform extensive numerical investigations using a wide range of examples to verify whether the distribution-free order rule indeed performs well for all realistic parameter settings. Moreover, we will explore which, if any, extreme parameter values cause the distribution-free order rule to be far from optimal. We remark that in previous studies the distribution-free order rule has never been tested for the lognormal distribution, which is one of the three standard distributions that we use here.

We assume that the gross demand distribution is normal, uniform or lognormal with mean $\mu_{G}$ and standard deviation $\sigma_{G}$. We compare the distribution-free order quantity $\widetilde{Q}$ in $(4)$ to the optimal order quantity $Q^{\star}$ in (2). We also compare the associated expected profits, which are computed using equation (1). There, $\mu_{N}$ is replaced by the mean of the 5000 'net drawings' $n_{i}$ that are constructed as explained in the previous section and the expected net shortage is computed as $E S_{N}(Q)=\sum_{i} 1 / 5000\left[n_{i}-Q\right]^{+}$. The parameter values that we have used in our computations are shown in Table 2. We have used all possible combinations of these values.

Tables $3 \mathrm{a}$ and $3 \mathrm{~b}$ display the results for $\mu_{G}=150$. The results for higher values of the expected gross demand are similar in pattern and size of the percentage differences in order quantities and expected profits. When the return percentage rises above $80 \%$, it is impossible to make a profit unless the relative profit margin (RPM) is very high. Thus, the order quantities are zero in this case. Therefore, we can only show the results for return percentages up to $75 \%$. As the tables show, it is already impossible to make a profit when $r=0.75$ and $\mathrm{RPM}=0.5$. We first look at the results for all 3 distributions for coefficient of variation (CV) equal to 0.1 and 0.5 (Table 3a). Then we discuss the results for the lognormal distribution for higher values of the CV (Table 3b).

For $\mathrm{CV}=0.1$, the distribution free order rule performs excellent for all 3 distributions. The distribution-free order quantity differs slightly, up to $-3 \%$ or $+1 \%$, from the optimal order quantity. However, this difference does not lead to a considerable loss in expected profit (less than $1 \%)$. 
For $\mathrm{CV}=0.5$, the performance of the distribution free order rule is well in most cases for all 3 distributions, but there are cases where the loss in expected profit is 3 or 4 percent. For the lognormal distribution, the percentage deviation of $\widetilde{Q}$ from $Q^{\star}$ is always positive and significantly rises when the relative profit margin decreases. When the relative profit margin is 0.5 , the maximum deviation is $14 \%$, leading to a loss in expected profit of $3 \%$. For the normal distribution, a low relative profit margin leads to a positive deviation of $\widetilde{Q}$ from $Q^{\star}$ of at most $7 \%$, while this deviation is negative (around -4\%) for larger relative profit margins. Contrary to the lognormal case, this deviation increases with the return rate, though only when the deviation is positive. The same holds for the uniform distribution, which however shows significantly larger differences between the order quantities. $\widetilde{Q}$ is $6 \%$ to $20 \%$ larger than $Q^{\star}$ when $\mathrm{RPM}=0.5$, while it is on average $8 \%$ lower for higher relative profit margins. The loss in expected profit is at most $1 \%$, except when the return rate is high and the relative profit margin low, in which case the loss is $4 \%$.

The distribution-free order rule performs poor when the coefficient of variation of gross demand is 1 or larger. For $\mathrm{CV}=1$, the distribution-free order quantity is on average $27 \%$ larger than the optimal order quantity given lognormal gross demand. Unless the relative profit margin is very high, this leads to significant losses in expected profit of up to $14 \%$. These differences grow even larger when uncertainty is very high $(\mathrm{CV}=2)$. In that case, the differences in order quantities are huge (up to 135\%) and the average loss in expected profit from using the distribution-free order rule is $38 \%$. Given $R P M=0.5$, the percentual deviation of $\widetilde{Q}$ from $Q^{\star}$ falls sharply when $r$ rises, from $+110 \%$ for $r=0.01$ to $-41 \%$ for $r=0.5$. For larger relative profit margins, this effect is opposite: the positive deviation of $\widetilde{Q}$ from $Q^{\star}$ rises with $r$.

\section{Conclusion}

We derived a simple closed-form formula that determines the order quantity for the distributionfree single-period (newsboy) inventory problem with returns in which only the mean and variance of gross demand are known. In order to account for the returns, the distribution-free order quantity was derived using a net demand approach. We compared the distribution-free order quantity to the optimal order quantity under the assumption that the gross demand distribution is either normal, lognormal or uniform. In order to be able to determine the optimal order quantity, we assumed that net demand follows the same type of distribution as gross demand. This assumption was validated in section 3 by comparing the simulated cdf of net demand to the normal, lognormal and uniform cdf with the same mean and standard deviation for a large 
number of examples.

Using wide ranges of the relevant parameters, we compared the distribution-free and optimal order quantities and their respective expected profits. It turned out that for a small coefficient of variation $(\mathrm{CV}=0.1)$, the distribution-free order quantity differs around 1\% (positive or negative) from the optimal order quantity in most cases, while the associated differences in expected profits are negligible for all three distributions. When the coefficient of variation is 0.5, the distribution-free order quantity is often far from optimal (up to $+20 \%$ from the optimal order quantity), especially for the lognormal and uniform distribution and when the relative profit margin is small. However, the loss in expected profit is still small, around $1 \%$ on average for the lognormal and uniform distributions and even less for the normal distribution. When the coefficient of variation is greater than or equal to 1 , the distribution-free order quantity is far from optimal and often also results in a considerable loss in expected profit (of up to $72 \%$ ).

Based on these results, we recommend the following to firms that face returns and have to determine single period order quantities based on limited available data. For products with a coefficient of variation of gross demand $(\mathrm{CV})$ of at most 0.5 , just estimate the mean and standard deviation of gross demand and apply the distribution free order rule in (4). For products with a $\mathrm{CV}$ of more than 0.5 , try to estimate the entire distribution function and determine the optimal order quantity using (2). 


\section{References}

De Koster, R. and Zuidema, J. (2002). Dealing with large numbers of commercial returns at a mail order company. In Logistikplanung und-Management, pages 188-199.

Fisher, M. L. and Raman, A. (1996). Reducing the cost of demand uncertainty through accurate response to early sales. Operations Research, 44(1):87-99.

Fleischmann, M., Bloemhof-Ruwaard, J. M., Dekker, R., Van der Laan, E., Van Nunen, J., and Van Wassenhove, L. (1997). Quantitative models for reverse logistics: A review. European Journal of Operational Research, 103:1-17.

Gallego, G. (1992). A minmax distribution free procedure for the (Q,r) inventory model. Operations Research Letters, 11:55-60.

Gallego, G. and Moon, I. (1993). The distribution free newsboy problem: Review and extensions. Journal of the Operational Research Society, 44(8):825-834.

Jain, N. and Paul, A. (2001). A generalized model of operations reversal for fashion goods. Management Science, 47(4):595-600.

Kelle, P. and Silver, E. (1989). Forecasting the returns of reusable containers. Journal of Operations Management, 8(1):17-35.

Khouja, M. (1999). The single-period (news-vendor) problem: Literature review and suggestions for future research. Omega, The International Journal of Management Science, $27: 537-553$.

Mantrala, M. K. and Raman, K. (1999). Demand uncertainty and supplier's returns policies for a multi-store style-good retailer. European Journal of Operational Research, 115:270-284.

Moon, I. and Choi, S. (1995). The distribution free newsboy problem with balking. Journal of the Operational Research Society, 46(4):537-542.

Moon, I. and Choi, S. (1998). A note on lead time and distributional assumptions in continuous review inventory models. Computers and Operations Research, 25(11):1007-1012.

Mostard, J. and Teunter, R. (2002). The newsboy problem with resalable returns. Technical Report ERS-2002-89-LIS, Erasmus Research Institute of Management (ERIM), Erasmus University Rotterdam. 
Revlog (the European Working Group on Reverse Logistics) website (1999). http://www.fbk.eur.nl/oz/revlog/.

Rogers, D. and Tibben-Lembke, R. (1999). Going Backwards: Reverse Logistics Trends and Practices. Reverse Logistics Executive Council, Pittsburgh, PA.

Scarf, H. (1958). A min-max solution of an inventory problem. In Arrow, K. J., Karlin, S., and Scarf, H., editors, Studies in the Mathematical Theory of Inventory and Production, pages 201-209. Stanford University Press.

Silver, E. A. and Moon, I. (2001). The multi-item single period problem with an initial stock of convertible units. European Journal of Operational Research, 132:466-477.

Silver, E. A., Pyke, D. F., and Peterson, R. (1998). Inventory Management and Production Planning and Scheduling. John Wiley \& Sons, New York, third edition.

Vlachos, D. and Dekker, R. (2003). Return handling options and order quantities for single period products. European Journal of Operational Research, 151:38-52. 


\section{A Derivation and uniqueness of the optimal distribution- free order quantity}

Let $x=\frac{c-v}{p_{N}-v+g_{N}}$. Setting the derivative of (3) to zero and solving for $Q$ gives

$$
\begin{aligned}
0= & c-v+\frac{1}{4}\left(p_{N}-v+g_{N}\right)\left(\sigma_{N}^{2}+\left(Q-\mu_{N}\right)^{2}\right)^{-\frac{1}{2}} \cdot 2\left(Q-\mu_{N}\right) \\
& -\frac{1}{2}\left(p_{N}-v+g_{N}\right) .
\end{aligned}
$$

Thus,

$$
\frac{Q-\mu_{N}}{\sqrt{\sigma_{N}^{2}+\left(Q-\mu_{N}\right)^{2}}}=1-\frac{2(c-v)}{p_{N}-v+g_{N}}=1-2 x .
$$

This gives

$$
\left(Q-\mu_{N}\right)^{2}\left(1-(1-2 x)^{2}\right)=\sigma_{N}^{2}(1-2 x)^{2}
$$

and therefore

$$
Q=\mu_{N}+\frac{(1-2 x) \sigma_{N}}{\sqrt{1-\left(1-4 x+4 x^{2}\right)}}=\mu_{N}+\frac{(1-2 x) \sigma_{N}}{\sqrt{4 x(1-x)}}=\mu_{N}+\frac{\sigma_{N}}{2} \frac{1-2 x}{\sqrt{x(1-x)}},
$$

which yields (4).

Let $e=Q-\mu_{N}$ and $f=p_{N}-v+g_{N}$. The second derivative of (3) equals

$$
\begin{gathered}
-\frac{1}{4} \frac{f}{\left(\sigma_{N}^{2}+e^{2}\right) \sqrt{\sigma_{N}^{2}+e^{2}}} \cdot 2 e \cdot e+\frac{f}{2 \sqrt{\sigma_{N}^{2}+e^{2}}} \\
=\frac{f}{2 \sqrt{\sigma_{N}^{2}+e^{2}}}-\frac{f e^{2}}{2\left(\sigma_{N}^{2}+e^{2}\right) \sqrt{\sigma_{N}^{2}+e^{2}}} \\
=\frac{f \sigma_{N}^{2}}{2\left(\sigma_{N}^{2}+e^{2}\right) \sqrt{\sigma_{N}^{2}+e^{2}}} .
\end{gathered}
$$

\section{B Parameter calculation for different demand distribu- tions}

Given mean $\mu_{G}$ and variance $\sigma_{G}^{2}$ of gross demand and assuming that gross demand follows a lognormal or uniform distribution, the parameters of the lognormal and uniform distributions can be computed as described below.

\section{B.1 Lognormal distribution}

The pdf of the lognormal distribution is

$$
f(x)= \begin{cases}\frac{\exp \left(-1 / 2((\ln x-m) / s)^{2}\right)}{x \sqrt{2 \pi}} & \text { if } x>0 \\ 0 & \text { otherwise }\end{cases}
$$


The mean and variance of the lognormal distribution are

$$
e^{\left(2 m+s^{2}\right) / 2} \quad \text { and } \quad e 2 m+2 s^{2}-e^{2 m+s^{2}}
$$

We need those values of $m$ and $s$ for which the lognormal mean and variance equal $\mu_{G}$ and $\sigma_{G}^{2}$ respectively, i.e. those values for which

$$
e^{\left(2 m+s^{2}\right) / 2}=\mu_{G}
$$

and

$$
e^{2 m+2 s^{2}}-e^{2 m+s^{2}}=\sigma_{G}^{2}
$$

From (6), we get

$$
2 \ln \mu_{G}=2 m+s^{2} .
$$

Substituting this in (7) gives

$$
\mu_{G}^{2}\left(e^{s^{2}}-1\right)=\sigma_{G}^{2}
$$

and therefore,

$$
s=\sqrt{\ln \left(1+C V^{2}\right)} .
$$

Substituting (9) into (8) yields

$$
m=\ln \mu_{G}-\frac{1}{2} \ln \left(1+C V^{2}\right) .
$$

\section{B.2 Uniform distribution}

The uniform distribution has pdf

$$
g(x)= \begin{cases}\frac{1}{b-a} & \text { if } a<x<b \\ 0 & \text { otherwise }\end{cases}
$$

and mean and variance

$$
(a+b) / 2 \quad \text { and } \quad(b-a)^{2} / 12 .
$$

We need those values of $m$ and $s$ for which the uniform mean and variance equal $\mu_{G}$ and $\sigma_{G}^{2}$ respectively, i.e. those values for which

$$
(a+b) / 2=\mu_{G}
$$


and

$$
(b-a)^{2} / 12=\sigma_{G}^{2} .
$$

Rewriting (11) gives

$$
a=2 \mu_{G}-b .
$$

Substituting this into (12) gives

$$
\sigma_{G}^{2}=\left(2\left(b-\mu_{G}\right)\right)^{2} / 12=1 / 3\left(b-\mu_{G}\right)^{2},
$$

and thus

$$
b=\mu_{G}+\sqrt{3} \sigma_{G} .
$$

Now, (13) and (14) together yield

$$
a=\mu_{G}-\sqrt{3} \sigma_{G} .
$$

\section{Tables and figures}




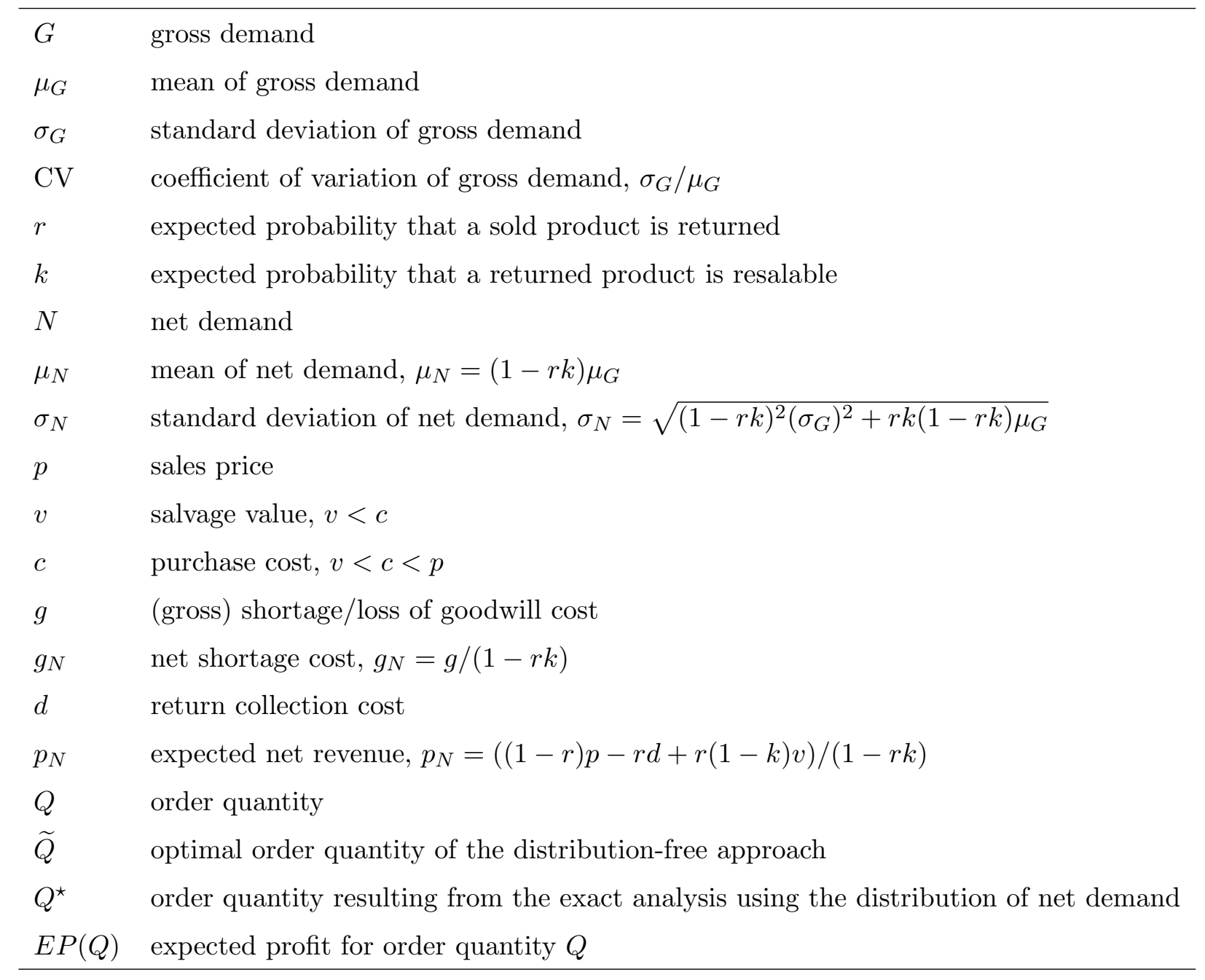

Table 1: Notations.

\begin{tabular}{r|c} 
& used parameter values \\
\hline expected gross demand, $\mu_{G}$ & $150,500,2000$ \\
$\mathrm{CV}$ of gross demand, $\sigma_{G} / \mu_{G}$ & $0.1,0.5,1,2$ \\
return rate, $r$ & $0.01,0.05,0.25,0.5,0.75,0.95,0.97,0.99$ \\
relative profit margin, $(p-c) / c$ & $0.5,1.5,4$
\end{tabular}

Table 2: Parameter values that are used in the computational experiments. $c=20, v=$ $c / 3, d=4.25$ and $g=0$ for all products. 

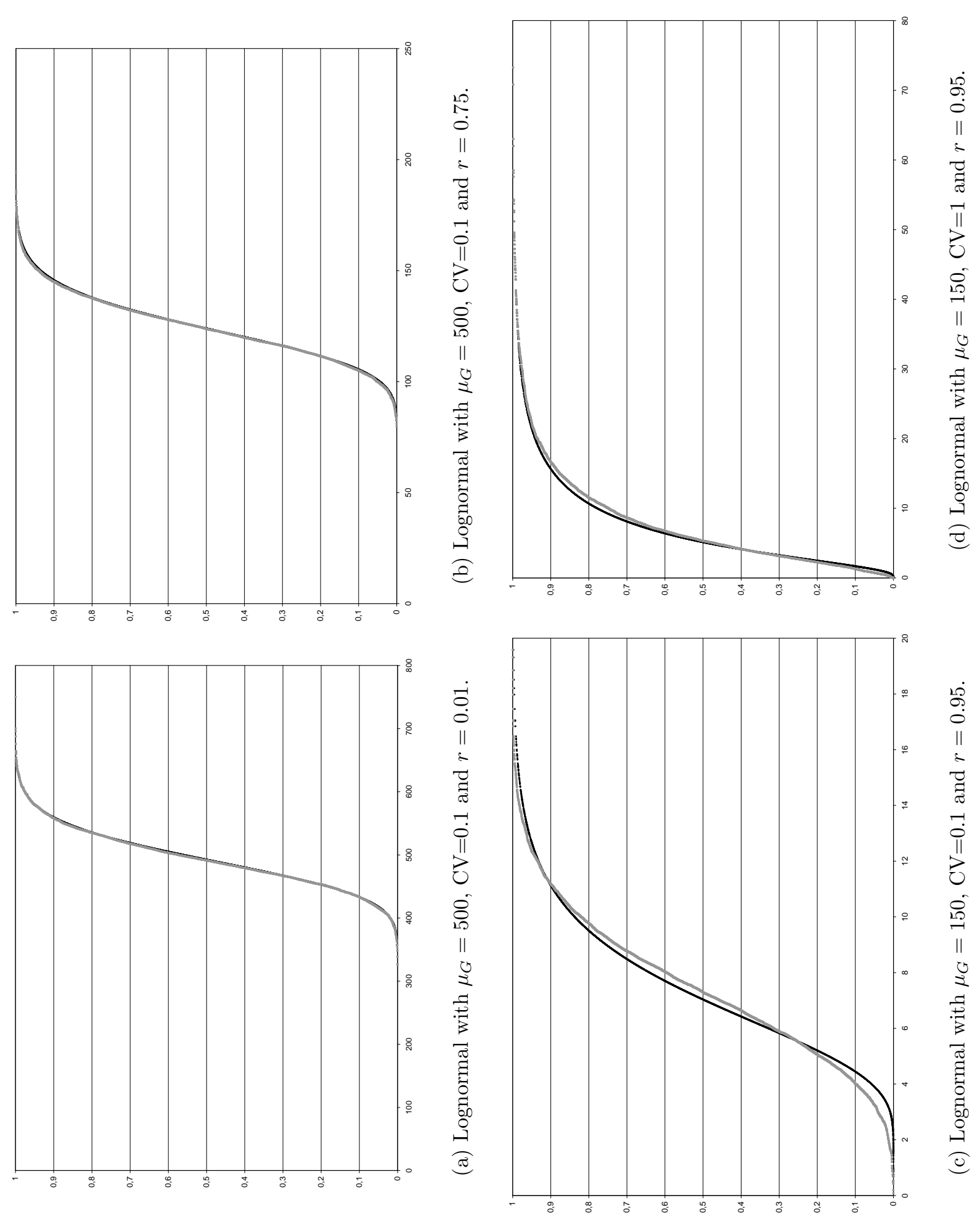

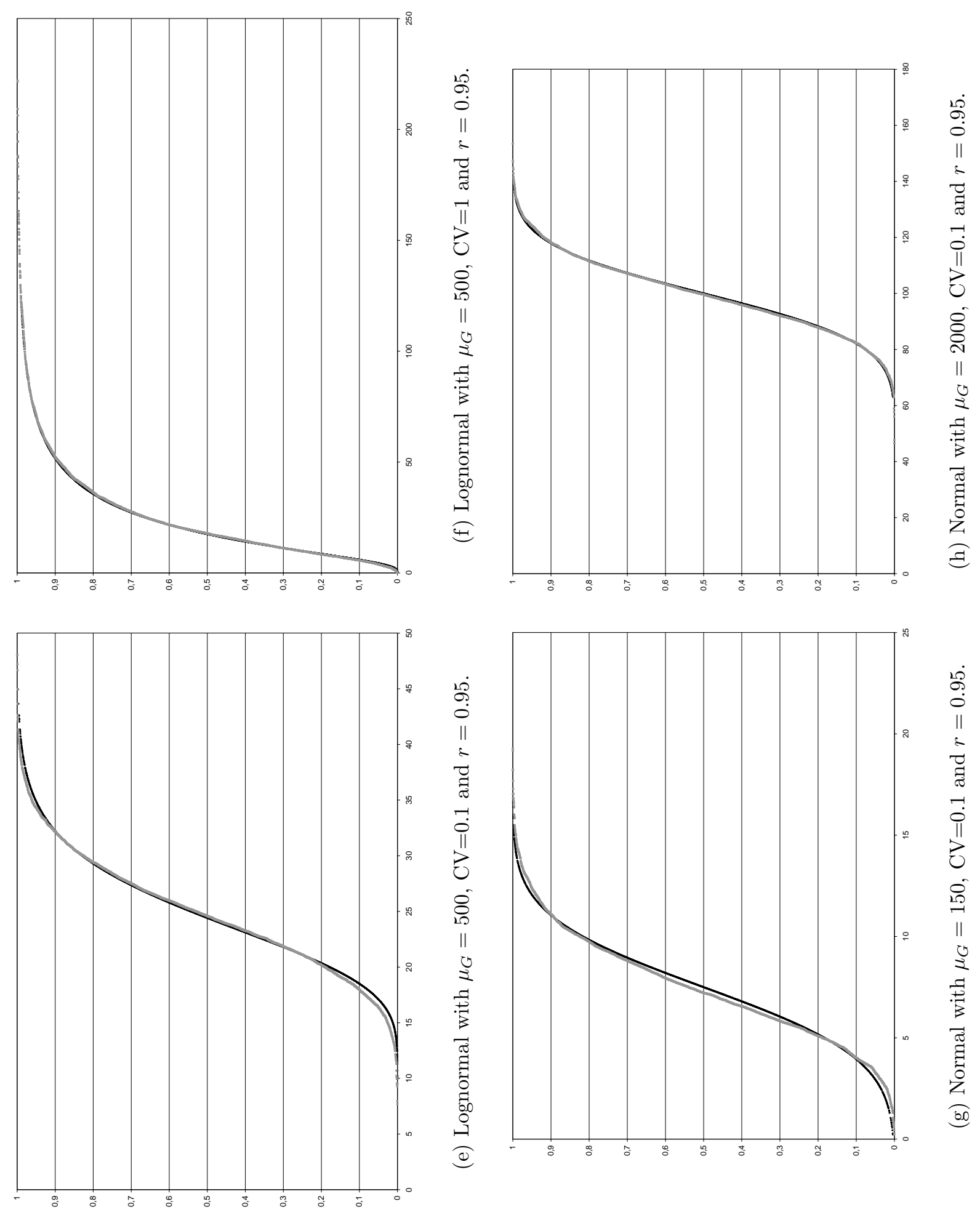


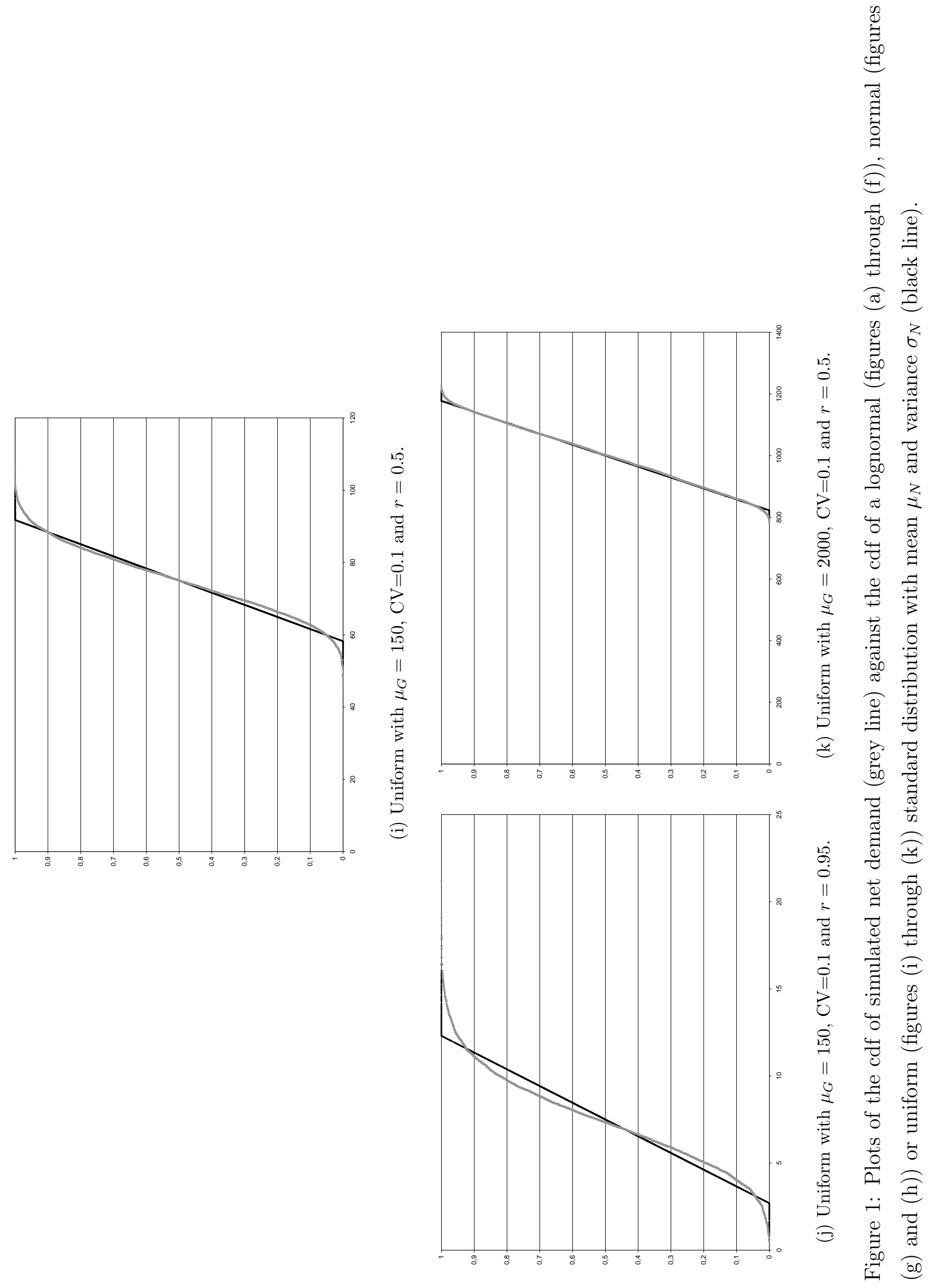




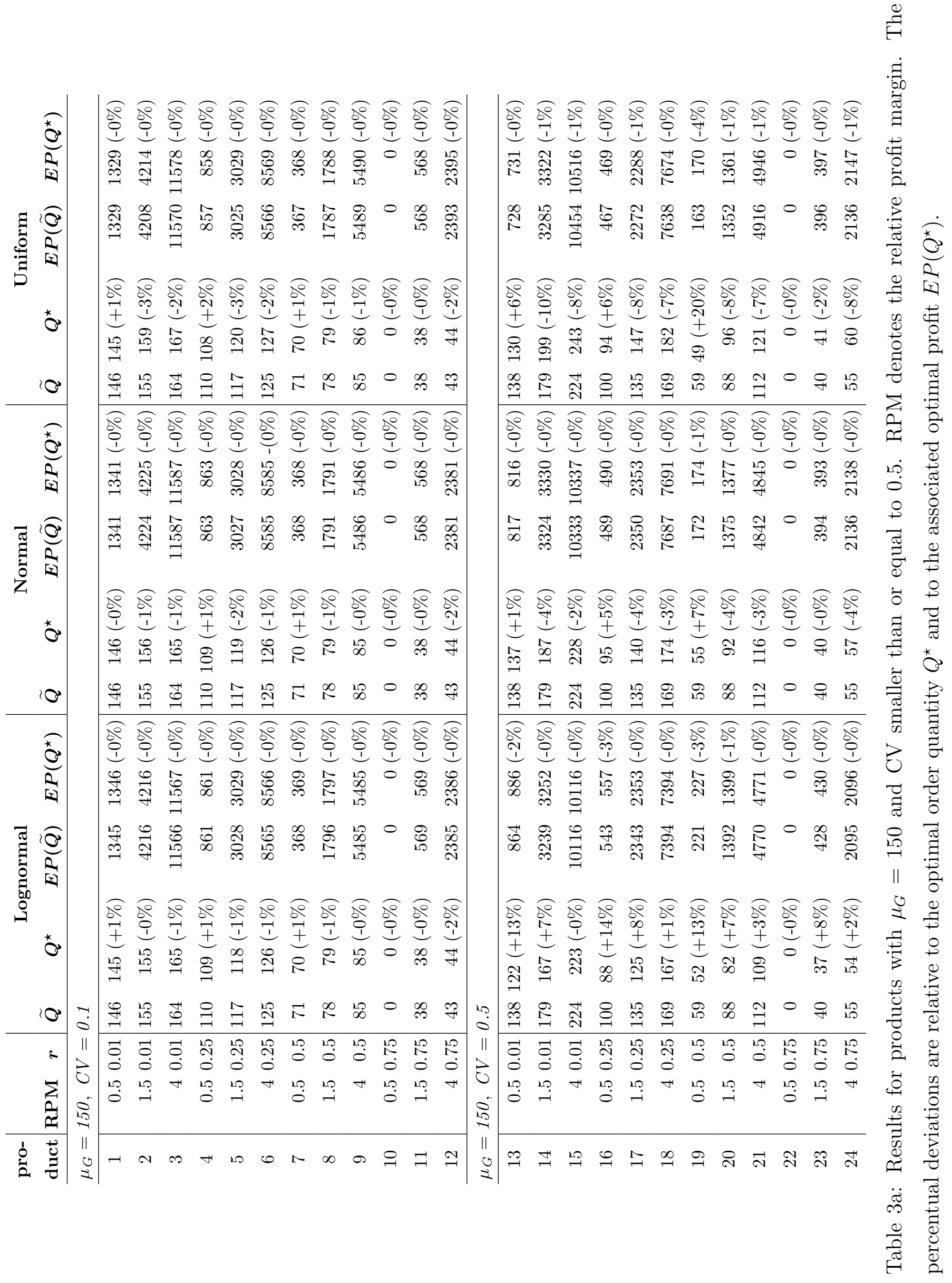




\begin{tabular}{|c|c|c|c|c|c|c|c|c|c|c|c|}
\hline \multirow{2}{*}{$\begin{array}{l}\text { pro- } \\
\text { duct }\end{array}$} & \multirow{2}{*}{ RPM } & \multirow[b]{2}{*}{$r$} & \multicolumn{4}{|c|}{ Lognormal, $\mathrm{CV}=1$} & \multirow{2}{*}{$\begin{array}{l}\text { pro- } \\
\text { duct }\end{array}$} & \multicolumn{4}{|c|}{ Lognormal, $\mathrm{CV}=2$} \\
\hline & & & $\widetilde{Q}$ & $Q^{\star}$ & $\operatorname{EP}(\widetilde{Q})$ & $\operatorname{EP}\left(Q^{\star}\right)$ & & $\widetilde{Q}$ & $Q^{\star}$ & $\operatorname{EP}(\widetilde{Q})$ & $\operatorname{EP}\left(Q^{\star}\right)$ \\
\hline \multicolumn{8}{|c|}{$\mu_{G}=150, C V=1$} & \multicolumn{4}{|c|}{$\mu_{G}=150, C V=2$} \\
\hline 25 & 0.5 & 0.01 & 127 & $90(+41 \%)$ & 460 & $533(-14 \%)$ & 37 & 105 & $50(+110 \%)$ & 66 & $238(-72 \%)$ \\
\hline 26 & 1.5 & 0.01 & 210 & $159(+32 \%)$ & 2238 & $2365(-5 \%)$ & 38 & 272 & $129(+111 \%)$ & 802 & $1443(-44 \%)$ \\
\hline 27 & 4 & 0.01 & 300 & $264(+14 \%)$ & 8304 & $8360(-1 \%)$ & 39 & 452 & $264(+71 \%)$ & 5057 & $5863(-14 \%)$ \\
\hline 28 & 0.5 & 0.25 & 87 & $65(+34 \%)$ & 298 & $334(-11 \%)$ & 40 & 63 & $34(+85 \%)$ & 86 & $150(-43 \%)$ \\
\hline 29 & 1.5 & 0.25 & 156 & $118(+32 \%)$ & 1611 & $1703(-5 \%)$ & 41 & 200 & $91(+120 \%)$ & 515 & $997(-48 \%)$ \\
\hline 30 & 4 & 0.25 & 226 & $196(+15 \%)$ & 6064 & $6113(-1 \%)$ & 42 & 339 & $193(+76 \%)$ & 3666 & $4285(-14 \%)$ \\
\hline 31 & 0.5 & 0.5 & 42 & $35(+20 \%)$ & 119 & $124(-4 \%)$ & 43 & 10 & $17(-41 \%)$ & 43 & $52(-17 \%)$ \\
\hline 32 & 1.5 & 0.5 & 100 & $76(+32 \%)$ & 928 & $982(-5 \%)$ & 44 & 125 & $55(+127 \%)$ & 256 & $569(-55 \%)$ \\
\hline 33 & 4 & 0.5 & 149 & $126(+18 \%)$ & 3832 & $3873(-1 \%)$ & 45 & 222 & $126(+76 \%)$ & 2320 & $2728(-15 \%)$ \\
\hline 34 & 0.5 & 0.75 & 0 & $0(-0 \%)$ & 0 & $0(-0 \%)$ & 46 & 0 & $0(-0 \%)$ & 0 & $0(-0 \%)$ \\
\hline 35 & 1.5 & 0.75 & 42 & $30(+40 \%)$ & 257 & $284(-10 \%)$ & 47 & 47 & $20(+135 \%)$ & 38 & $149(-74 \%)$ \\
\hline 36 & 4 & 0.75 & 72 & $60(+20 \%)$ & 1653 & $1675(-1 \%)$ & 48 & 105 & $57(+84 \%)$ & 932 & $1140(-18 \%)$ \\
\hline
\end{tabular}

Table 3b: Results for products with $\mu_{G}=150$ and CV greater than or equal to 1 . RPM denotes the relative profit margin. The percentual deviations are relative to the optimal order quantity $Q^{\star}$ and to the associated optimal profit $E P\left(Q^{\star}\right)$. 


\section{Publications in the Report Series Research* in Management}

ERIM Research Program: "Business Processes, Logistics and Information Systems"

2003

Project Selection Directed By Intellectual Capital Scorecards

Hennie Daniels and Bram de Jonge

ERS-2003-001-LIS

http://hdl.handle.net/1765/265

Combining expert knowledge and databases for risk management

Hennie Daniels and Han van Dissel

ERS-2003-002-LIS

http://hdl.handle.net/1765/266

Recursive Approximation of the High Dimensional max Function

Ş. II. Birbil, S.-C. Fang, J.B.G. Frenk and S. Zhang

ERS-2003-003-LIS

http://hdl.handle.net/1765/267

Auctioning Bulk Mobile Messages

S.Meij, L-F.Pau, E.van Heck

ERS-2003-006-LIS

http://hdl.handle.net/1765/274

Induction of Ordinal Decision Trees: An MCDA Approach

Jan C. Bioch, Viara Popova

ERS-2003-008-LIS

http://hdl.handle.net/1765/271

A New Dantzig-Wolfe Reformulation And Branch-And-Price Algorithm For The Capacitated Lot Sizing Problem With Set Up Times

Zeger Degraeve, Raf Jans

ERS-2003-010-LIS

http://hdl.handle.net/1765/275

Reverse Logistics - a review of case studies

Marisa P. de Brito, Rommert Dekker, Simme D.P. Flapper

ERS-2003-012-LIS

http://hdl.handle.net/1765/277

Product Return Handling: decision-making and quantitative support

Marisa P. de Brito, M. (René) B. M. de Koster

ERS-2003-013-LIS

http://hdl.handle.net/1765/278

\footnotetext{
A complete overview of the ERIM Report Series Research in Management: $\underline{\text { http://www.erim.eur.nl }}$

ERIM Research Programs:

LIS Business Processes, Logistics and Information Systems

ORG Organizing for Performance

MKT Marketing

F\&A Finance and Accounting

STR Strategy and Entrepreneurship
} 
Managing Product Returns: The Role of Forecasting

Beril Toktay, Erwin A. van der Laan, Marisa P. de Brito

ERS-2003-023-LIS

http://hdl.handle.net/1765/316

Improved Lower Bounds For The Capacitated Lot Sizing Problem With Set Up Times

Zeger Degraeve, Raf Jans

ERS-2003-026-LIS

http://hdl.handle.net/1765/326

In Chains? Automotive Suppliers and Their Product Development Activities

Fredrik von Corswant, Finn Wynstra, Martin Wetzels

ERS-2003-027-LIS

http://hdl.handle.net/1765/363

Mathematical models for planning support

Leo G. Kroon, Rob A. Zuidwijk

ERS-2003-032-LIS

http://hdl.handle.net/1765/332

How and why communications industry suppliers get "squeezed out" now, and the next phase

L-F Pau

ERS-2003-033-LIS

http://hdl.handle.net/1765/317

Financial Markets Analysis by Probabilistic Fuzzy Modelling

Jan van den Berg, Uzay Kaymak, Willem-Max van den Bergh

ERS-2003-036-LIS

http://hdl.handle.net/1765/323

WLAN Hot Spot services for the automotive and oil industries :a business analysis or : "Refuel the car with petrol and information , both ways at the gas station "

L-F Pau, M.H.P.Oremus

ERS-2003-039-LIS

http://hdl.handle.net/1765/318

A Lotting Method for Electronic Reverse Auctions

U. Kaymak, J.P. Verkade and H.A.B. te Braake

ERS-2003-042-LIS

http://hdl.handle.net/1765/337

Supply Chain Optimisation in Animal Husbandry

J.M. Bloemhof, C.M. Smeets, J.A.E.E. van Nunen

ERS-2003-043-LIS

http://hdl.handle.net/1765/353

A Framework for Reverse Logistics

Marisa P. de Brito and Rommert Dekker

ERS-2003-045-LIS

http://hdl.handle.net/1765/354

An assessment system for rating scientific journals in the field of ergonomics and human factors Jan Dul and Waldemar Karwowski

ERS-2003-048-LIS

http://hdl.handle.net/1765/432 
Circulation of Railway Rolling Stock: A Branch-and-Price Approach

Marc Peeters and Leo Kroon

ERS-2003-055-LIS

http://hdl.handle.net/1765/902

Emerging Multiple Issue e-Auctions

Jeffrey E. Teich, Hannele Wallenius, Jyrki Wallenius and Otto R. Koppius

ERS-2003-058-LIS

http://hdl.handle.net/1765/922

Inventory Management with product returns: the value of information

Marisa P. de Brito and E. A. van der Laan

ERS-2003-060-LIS

http://hdl.handle.net/1765/925

Promising Areas for Future Research on Reverse Logistics: an exploratory study

Marisa P. de Brito

ERS-2003-061-LIS

http://hdl.handle.net/1765/926

A Polynomial Time Algorithm for a Deterministis Joint Pricing and Inventory Model

Wilco van den Heuvel and Albert P.M. Wagelmans

ERS-2003-065-LIS

http://hdl.handle.net/1765/929

A geometric algorithm to solve the ni/g/ni/nd capacitated lot-sizing problem in o(t²) time Wilco van den Heuvel and Albert P.M. Wagelmans

ERS-2003-066-LIS

http://hdl.handle.net/1765/930

Arrival Processes for Vessels in a Port Simulation

Eelco van Asperen, Rommert Dekker, Mark Polman, Henk de Swaan Arons \& Ludo Waltman ERS-2003-067-LIS

http://hdl.handle.net/1765/973 